\title{
Wet-dry cycles impact DOM retention in subsurface soils
}

\author{
Yaniv Olshansky, Robert A. Root, and Jon Chorover \\ Department of Soil, Water and Environmental Science, University of Arizona, Tucson 85721, USA
}

Correspondence: Yaniv Olshansky (yanivo@email.arizona.edu)

Received: 23 June 2017 - Discussion started: 24 August 2017

Revised: 14 December 2017 - Accepted: 15 December 2017 - Published: 9 February 2018

\begin{abstract}
Transport and reactivity of carbon in the critical zone are highly controlled by reactions of dissolved organic matter (DOM) with subsurface soils, including adsorption, transformation and exchange. These reactions are dependent on frequent wet-dry cycles common to the unsaturated zone, particularly in semi-arid regions. To test for an effect of wetdry cycles on DOM interaction and stabilization in subsoils, samples were collected from subsurface $(\mathrm{Bw})$ horizons of an Entisol and an Alfisol from the Catalina-Jemez Critical Zone Observatory and sequentially reacted (four batch steps) with DOM extracted from the corresponding soil litter layers. Between each reaction step, soils either were allowed to air dry ("wet-dry" treatment) before introduction of the following DOM solution or were maintained under constant wetness ("continually wet" treatment). Microbial degradation was the dominant mechanism of DOM loss from solution for the Entisol subsoil, which had higher initial organic C content, whereas sorptive retention predominated in the lower C Alfisol subsoil. For a given soil, bulk dissolved organic C losses from solution were similar across treatments. However, a combination of Fourier transform infrared (FTIR) and near-edge X-ray absorption fine structure (NEXAFS) spectroscopic analyses revealed that wet-dry treatments enhanced the interactions between carboxyl functional groups and soil particle surfaces. Scanning transmission X-ray microscopy (STXM) data suggested that cation bridging by $\mathrm{Ca}^{2+}$ was the primary mechanism for carboxyl association with soil surfaces. STXM data also showed that spatial fractionation of adsorbed OM on soil organo-mineral surfaces was diminished relative to what might be inferred from previously published observations pertaining to DOM fractionation on reaction with specimen mineral phases. This study provides direct evidence of the role of wet-dry cycles in affecting sorption reactions of DOM to a complex soil matrix. In the soil environment, where wet-dry cycles occur at dif-
\end{abstract}

ferent frequencies from site to site and along the soil profile, different interactions between DOM and soil surfaces are expected and need to be considered for the overall assessment of carbon dynamics.

\section{Introduction}

Dissolved organic matter (DOM) is the main vehicle of organic carbon (OC) and nutrient transport to the subsoil (Kaiser and Kalbitz, 2012; Kalbitz et al., 2000). There it stimulates key biogeochemical processes including heterotrophic microbial activity (Fontaine et al., 2007), mineral transformation and organic and inorganic nutrient and contaminant mobilization (Chorover et al., 2007; Polubesova and Chefetz, 2014; Zhao et al., 2011). Interactions with subsoil surfaces act to stabilize DOM against advective transport and microbial degradation (Eusterhues et al., 2014; Kalbitz et al., 2000; Lutzow et al., 2006). Furthermore, prior studies have shown that DOM generated in the surface litter layers can be transported preferentially to clay-enriched subsoils via macropore flow paths that bypass the intervening matrix (Rumpel and Kögel-Knabner, 2010). Particularly in semi-arid vadose zones, these DOM-subsoil interactions occur in a context of frequent wet-dry cycles. Although such cyclic conditions likely impact $\mathrm{C}$ dynamics, the nature of their effects on micro- to molecular-scale organo-mineral associations remains poorly known.

The principal chemical mechanisms affecting DOM retention at soil particle surfaces, including ligand exchange with surface hydroxyl groups, ion exchange of organic moieties at charged sites, cation bridging, hydrogen bonding and van der Waals interactions, depend on both DOM molecular composition and mineral surface chemistry (Chorover and Amistadi, 2001; Gu et al., 1994; Kleber et al., 2007, 2014). In- 
teractions of DOM with dissolved polyvalent cations (e.g., $\mathrm{Fe}^{3+}$ and $\mathrm{Al}^{3+}$ ) may also result in its coagulation and coprecipitation with nucleating metal (oxy)hydroxides (Chen et al., 2014a; Eusterhues et al., 2011). Drying of OM-mineral complexes can affect the mode of interaction. These effects may include changing of adsorption mode and product surface chemistry. For example, drying can convert OM adsorbate from outer- to inner-sphere coordination (Kang et al., 2008), promote exposure of hydrophobic functional groups of the adsorbed species and increase surface catalyzed transformation reactions (Olshansky et al., 2014). For systems where cation bridging plays a prominent role in DOM adsorption (e.g., to the siloxane surfaces of $2: 1$ layer type clay minerals), cation charge and valence effects are important, with increasing exchangeable $\mathrm{Ca}^{2+}$ relative to $\mathrm{Na}^{+}$, resulting in greater DOM retention (Setia et al., 2013).

Due to the heterogeneous nature of both DOM and soil mineral constituents, fractionation of DOM occurs as a result of a gradient of interaction affinities between the DOM components and various soil particle surfaces (Kaiser et al., 1997; Oren and Chefetz, 2012a). DOM fractionation has been studied extensively on single mineral phases (Chorover and Amistadi, 2001; Vazquez-Ortega et al., 2014) and on bulk soils (Guo and Chorover, 2003; Kaiser et al., 1997; Oren and Chefetz, 2012b). Metal (oxy)hydroxides have been suggested as a dominant adsorbent for DOM with the result being preferential retention of high molar mass aromatic and carboxylated moieties (Chorover and Amistadi, 2001; Vazquez-Ortega et al., 2014). Conversely, layered silicates (e.g., smectites, kaolinite) were reported to adsorb mainly low molar mass and aliphatic DOM fractions (Chorover and Amistadi, 2001; Polubesova et al., 2008). While the use of specimen mineral phases in adsorption experiments facilitates elucidation of molecular mechanisms of DOM interaction, it does not account for the complexity of competitive interactions associated with heterogeneous assemblies of weathered surfaces as found in natural soils. Conversely, using whole soils in adsorption experiments has traditionally hindered mechanistic interpretations of DOM uptake results. However, increased spatial resolution of spectroscopic methods has helped to overcome these shortcomings by providing micro- and nanoscale information on both soilmineral phases and associated organic molecules (Chen et al., 2014b).

The current study aimed to utilize such methodological advances to elucidate (i) how wet-dry cycles affect the reactions between DOM and subsoil particle surfaces and (ii) whether spatial fractionation of DOM is detectable with nanoscale resolution spectroscopic methods. We hypothesized that discontinuous wet-dry cycling during DOM reaction with subsoils would increase complexation of carboxyl groups with metal (oxy)hydroxide surfaces or hydroxylated edge surfaces of aluminosilicate clays and promote association of hydrophobic fractions with pre-adsorbed and desiccated DOM components relative to continuously wet condi- tions. Such wetting-drying episodes have been hypothesized to affect OC dynamics in water-limited portions of the critical zone, such as those that occur in the semi-arid southwestern USA (Miller et al., 2005; Perdrial et al., 2014), but they have not been previously investigated in controlled laboratory experiments.

\section{Materials and methods}

\subsection{Soil samples}

Soils were sampled from below a mixed conifer forest in the Santa Catalina Mountains (SCM) and Jemez River Basin (JRB) critical zone observatories (CZOs) in Arizona and New Mexico, respectively (Chorover et al., 2011). The JRB soil was collected from the south slope of San Antonio Mountain $\left(35^{\circ} 55^{\prime} 10^{\prime \prime} \mathrm{N}, 106^{\circ} 36^{\prime} 52^{\prime \prime} \mathrm{W}\right)$ at an elevation of $2750 \mathrm{~m}$. The SCM soil was collected from the northeast slope of the zero-order basin located in the Marshall Gulch experimental site $\left(32^{\circ} 25^{\prime} 44^{\prime \prime} \mathrm{N}, 110^{\circ} 46^{\prime} 14^{\prime \prime} \mathrm{W}\right)$ at elevation of $2600 \mathrm{~m}$. The mean annual temperature is 6 and $10.4^{\circ} \mathrm{C}$ for the JRB and SCM sites, respectively. Both sites are subjected to bimodal annual precipitation patterns with averages of 850 and $940 \mathrm{~mm} \mathrm{yr}^{-1}$. Parent rock is igneous felsic at both sites, and granitic in the SCM and rhyolitic in the JRB. Therefore, the soils used in experiments developed under similar vegetation and climatic conditions but in different parent materials. The SCM and JRB soils are classified as Typic Ustorthents and mixed Psammentic Cryoboralfs, respectively (Soil Survey Staff, 2010; USDA-NRCS, 1999). Soils were collected from the litter layer $(0-2 \mathrm{~cm})$ and $\mathrm{Bw} 3$ horizon $(80-100 \mathrm{~cm})$, from pedons excavated (one in each site) in April 2012 and October 2015 for SCM and JRB, respectively. The samples were collected from different locations within each pit and composited to one representative local sample. The SCM litter layer was collected in October 2015. Soils were air dried and sieved to obtain the fine earth $(<2 \mathrm{~mm})$ fraction and stored in a closed container. Table 1 presents the bulk properties of the studied subsoils as measured using standard methods (Sparks, 1996). The mineral assemblages of both soils were dominated by quartz, feldspars and aluminosilicate clays (Table S1 in the Supplement). The SCM soil had higher OM content $\left(1.1 \pm 0.5 \mathrm{mg} \mathrm{C} \mathrm{mg}^{-1}\right)$ and lower $\mathrm{pH}(6.1 \pm 0.04)$ than the JRB soil $\left(0.17 \pm 0.2 \mathrm{mg} \mathrm{C} \mathrm{mg}^{-1}\right.$ and $7.05 \pm 0.11)$.

\subsection{Dissolved organic matter extraction}

The extraction of DOM was achieved by mixing the airdried and sieved JRB or SCM litter with ultrapure water $\left(1: 5 \mathrm{~g} \mathrm{~g}^{-1}\right)$, and placing the suspension on a reciprocal shaker at $150 \mathrm{rpm}$ for $24 \mathrm{~h}$. Suspensions were centrifuged at $15000 \mathrm{~g}$ for $30 \mathrm{~min}$ to separate the solids, using polypropylene copolymer (PPCO) centrifuge bottles. Adsorption or contamination of DOM from these bottles was measured to 
Table 1. Physicochemical characteristics of the study soils.

\begin{tabular}{lrr}
\hline & JRB & SCM \\
\hline Clay $(\%)$ & 33.9 & 22.6 \\
Silt $(\%)$ & 27.7 & 38.4 \\
Sand $(\%)$ & 38.4 & 50.9 \\
SSA $\left(\mathrm{m}^{2} \mathrm{~g}^{-1}\right)^{\mathrm{a}}$ & $16.6 \pm 0.2$ & $7.7 \pm 0.1$ \\
$\mathrm{CEC}\left(\mathrm{mmol}^{\mathrm{c}} \mathrm{kg}^{-1}\right)^{\mathrm{b}}$ & $86.6 \pm 4.2$ & $61.3 \pm 0.8$ \\
$\mathrm{OC}(\%)^{\mathrm{c}}$ & $0.17 \pm 0.02$ & $1.11 \pm 0.5$ \\
$\mathrm{pH}^{\mathrm{d}}$ & $7.05 \pm 0.11$ & $6.10 \pm 0.04$ \\
$\mathrm{EC}\left(\mu \mathrm{cm}^{-1}\right)^{\mathrm{d}}$ & $61.5 \pm 26.6$ & $36.8 \pm 8.8$ \\
$\mathrm{DOC}\left(\mathrm{mg} \mathrm{L}^{-1}\right)^{\mathrm{d}}$ & $3.59 \pm 0.82$ & $13.45 \pm 1.30$ \\
DOM pH & $6.97 \pm 0.06$ & $5.91 \pm 0.11$ \\
DOM EC $\left(\mu \mathrm{cm}^{-1}\right)$ & $170.7 \pm 10.2$ & $84.1 \pm 12.3$ \\
SUVA $\left(\mathrm{L} \mathrm{mol}^{-1} \mathrm{~cm}^{-1}\right)$ & $905 \pm 35$ & $539 \pm 105$ \\
$\mathrm{HIX}^{\mathrm{e}}$ & $1.5 \pm 0.1$ & $4.5 \pm 2.3$ \\
$\mathrm{FI}^{\mathrm{f}}$ & $1.40 \pm 0.04$ & $1.43 \pm 0.03$ \\
\hline
\end{tabular}

${ }^{a}$ BET-N $N_{2}$ specific surface area. ${ }^{b}$ Cation exchange capacity. ${ }^{c}$ Organic carbon. ${ }^{d}$ Obtained in soil aqueous extract $(1: 10$ with $8.2 \mathrm{M} \Omega$, Barnstead water). ${ }^{\mathrm{e}}$ Humification index. ${ }^{\mathrm{f}}$ Fluorescence index.

be negligible (Vazquez-Ortega et al., 2014). The supernatant solution was transferred into $50 \mathrm{~mL}$ PPCO centrifuge tubes and centrifuged again at $40000 \mathrm{~g}$ for $20 \mathrm{~min}$ to remove colloidal organic material and the inorganic clay fraction. Supernatant solutions were filtered through pre-combusted and cleaned $0.7 \mu \mathrm{m}$ glass fiber filters. Total organic carbon (TOC) was measured immediately after extraction (Shimadzu TOCVCSH, Columbia, MD) and solutions were diluted using ultrapure water to give initial dissolved organic carbon (DOC) concentrations of $45 \mathrm{mg} \mathrm{L}^{-1}$ (Table 1). DOM solutions were stored at $4{ }^{\circ} \mathrm{C}$ prior to use.

\subsection{Sequential batch experiments}

To model the effect of sequential hydrologic events delivering litter leachate to subsoils in the two CZO sites, subsoils were reacted in a set of four steps with DOM extracted from the litter layer of the corresponding profile. Thirty $\mathrm{mL}$ aliquots of DOM (DOC $\left.=45 \mathrm{mg} \mathrm{L}^{-1}\right)$ solution were mixed with $3.0 \mathrm{~g}$ of soil in $50 \mathrm{~mL}$ PPCO centrifuge tubes and agitated $(150 \mathrm{rpm}$, orbital shaker) at room temperature, in the dark. Preliminary kinetic experiments indicated an apparent equilibration time of $98 \mathrm{~h}$, and this was chosen as the equilibration time for each reactor vessel. Suspensions were centrifuged for $30 \mathrm{~min}$ at $40000 \mathrm{~g}$ and $28 \mathrm{~mL}$ was removed by careful pipetting just below the surface to avoid loss of solids, filtered through precombusted $0.7 \mu \mathrm{m}$ glass fiber filters and the solutions were stored at $4{ }^{\circ} \mathrm{C}$ for a maximum of $24 \mathrm{~h}$ prior to analysis, as discussed below. For continually wet treatments, a fresh $28 \mathrm{~mL}$ aliquot of DOM solution was added to each tube and suspensions agitated for an additional $98 \mathrm{~h}(28 \mathrm{~mL}$ was used because ca. $2 \mathrm{~mL}$ remained as entrained solution in the wet soil paste). For wet- dry treatments, the soil pastes were air dried for $24 \mathrm{~h}$ (drying was accomplished by directing a low-flow circulating dryair stream to promote desiccation), then an aliquot of $30 \mathrm{~mL}$ DOM solution was added to each tube and suspensions were re-agitated for $98 \mathrm{~h}$, for a total of four sequential reaction cycles. Three replicates were prepared for each soil and treatment combination. After the four sequential reaction cycles, soils were freeze-dried and total organic carbon and total nitrogen (TN) were measured using an ECS 4010 CHNSO analyzer (Costech, MI, Italy). During the experiment, samples were maintained under oxic conditions by equilibration with oxygenated headspace. It is important to note that microbial activity was not suppressed throughout the reaction steps.

\subsection{Characterization of DOM solutions before and after reaction}

Reacted and unreacted DOM solutions were characterized by the following suite of complementary analytical methods: soluble TOC and TN were determined by total elemental analyzer (Shimadzu TOC-L and TNM-L, Columbia, MD), absorbance spectra (190 to $655 \mathrm{~nm}$ ) were collected using a UV-Vis spectrometer (Shimadzu Scientific Instruments UV-2501PC, Columbia, MD, USA), fluorescence excitationemission matrices (EEMs) were obtained with a FluoroMax4 equipped with a $150 \mathrm{~W}$ Xe-arc lamp source (Horiba Jobin Yvon, Irvine CA, USA) and Fourier transform infrared (FTIR) spectra were collected using a Nicolet NEXUS 670 IR spectrometer (Madison, WI). The EEMs were acquired with excitation (Ex) from 200 to $450 \mathrm{~nm}$ and emission (Em) from 250 to $650 \mathrm{~nm}$ in $5 \mathrm{~nm}$ increments. Spectra were collected with Ex and Em slits at 5 and $2 \mathrm{~nm}$ bandwidths, respectively, and an integration time of $100 \mathrm{~ms}$. Ultrapure water blank EEMs were subtracted and fluorescence intensities were normalized to the area under the water Raman peak, collected at excitation $350 \mathrm{~nm}$. Additionally, an inner-filter correction was performed based on the corresponding UVVis scans (Murphy et al., 2013). Transmission FTIR spectra were collected with a $\mathrm{KBr}$ beam splitter and a deuterated triglycine sulfate (DTGS) detector. Aliquots of $2 \mathrm{~mL}$ of JRB DOM solutions were transferred onto IR transmissive Ge windows and dried under vacuum for $19 \mathrm{~h}$; spectra were collected in transmission mode. For SCM DOM, $2 \mathrm{~mL}$ aliquots were freeze-dried and mixed with IR-grade $\mathrm{KBr}$, then compressed into pellets. For each sample, 120 scans were collected over the spectral range of $400-4000 \mathrm{~cm}^{-1}$ at a resolution of $4 \mathrm{~cm}^{-1}$. Clean $\mathrm{Ge}$ windows and $\mathrm{KBr}$ pellets were used as background.

\subsection{Scanning transmission X-ray microscopy and near-edge $X$-ray adsorption fine structure (STXM-NEXAFS) analysis of soils}

Scanning transmission X-ray microscopy (STXM) and nearedge X-ray absorption fine structure (NEXAFS) analyses 
were conducted on clay-size isolates to avoid particulate organic matter and to overcome possible alteration of $\mathrm{C}$ speciation during preparation of thin sections (Chen et al., 2014b). Clay size fractions $(<2 \mu \mathrm{m})$ of the reacted and unreacted JRB soils were separated by sedimentation after dispersion in ultrapure water using a sonication bath. Samples for STXM analysis were prepared by depositing $5 \mu \mathrm{L}$ of diluted aqueous suspension onto a $\mathrm{Si}_{3} \mathrm{~N}_{4}$ window ( $75 \mathrm{~nm}$ thick) and airdried. The samples were analyzed by STXM on beamline 10ID-1 at the Canadian Light Source (CLS), a 2.9 GeV thirdgeneration synchrotron source. The microscope set up used a $25 \mathrm{~nm}$ Fresnel zone plate, which provided a maximum spatial resolution of ca. $30 \mathrm{~nm}$. Samples were kept under 1/6 atm of He during measurement.

Spatially resolved spectra were obtained by collecting stacks of images at energies below and above C $1 \mathrm{~s}, \mathrm{Ca} 2 \mathrm{p}$, Fe 2p, element edges. The dwell time was set to $1 \mathrm{~ms}$ and pixel sizes of $150 \mathrm{~nm}$. Incident energy was calibrated with $\mathrm{CO}_{2}$ at $290.74 \mathrm{eV}$.

The aXis2000 software package (Hitchcock et al., 2012) was used for STXM image and spectral processing. Stacks were aligned and converted to optical density using a clean area of the $\mathrm{Si}_{3} \mathrm{~N}_{4}$ window for normalization. Regions of interest (ROI) of $\mathrm{C}, \mathrm{Ca}$ and $\mathrm{Fe}$ were extracted from each stack by subtracting below the edge from the optical density (OD) maps. C NEXAFS spectra were extracted by averaging the pixels from the ROI. NEXAFS spectra were normalized and peak deconvolutions were performed using the ATHENA software package (Ravel and Newville, 2005). Peak assignments were based on Cody et al. $(1998,2008)$, Myneni (2002) and Urquhart et al. (1997).

\subsection{Data analysis}

Statistical analyses were performed using R software packages (Mangiafico, 2016). Data were checked for normality and equal variance. Means were tested using one-way ANOVA for parametric analysis and Kruskal-Wallis for nonparametric analysis. The differences between means were examined using Tukey's honest significant difference (HSD) or Dunn tests for parametric or non-parametric analyses, respectively. Parametric tests used to evaluate the difference of TOC, TN and C-to-N ratio between treatments, while nonparametric tests were used to evaluate UV-Vis and fluorescence data. The specific UV absorbance ( $\left.\mathrm{SUVA}_{254}\right)$ was calculated by normalizing absorbance at incident wavelength $254 \mathrm{~nm}$ by the cell path length $(1 \mathrm{~cm})$ and DOC concentration (M). Fluorescence index (FI, Eq. 1) and humification index (HIX, Eq. 2) values were calculated from the corrected EEMs (McKnight et al., 2001; Ohno, 2002) as follows:
$\mathrm{FI}_{\mathrm{Ex} 370}=\frac{I_{450}}{I_{500}}$

$\operatorname{HIX}_{\mathrm{Ex} 255}=\frac{\sum\left(I_{435 \rightarrow 480}\right)}{\sum\left(I_{300 \rightarrow 345}\right)}$,

where Ex is the excitation wavelength (nanometers) and $I$ is the fluorescence intensity at each wavelength.

Spectra collected by FTIR were background corrected using $\mathrm{KBr}$ pellets or the $\mathrm{Ge}$ transmission window as blanks and baseline corrected using the spline function in the OMNIC 8 software program (Thermo Nicolet Co., Madison, WI). Peak positions were determined using the second-order Savitzky-Golay method. The Voigt line shape (a convolution between mixed Gaussian and Lorentzian line shapes) was fitted to the peaks in the $850-1850 \mathrm{~cm}^{-1}$ region using Grams/AI 8.0 spectroscopy software (Thermo Electron Corporation). Changes in DOM molecular composition were evaluated by quantifying peak intensity ratios. Peak assignments were based on Socrates (2004), Mayo et al. (2004), Omoike and Chorover et al. (2004) and Abdulla et al. (2010).

\section{Results}

\subsection{Total OC and nitrogen}

The loss of DOC from solution per unit mass of soil was largely independent of reaction step and treatment. The mass loss of DOC upon reaction with SCM soil was $156 \pm 5$, $217 \pm 3,167 \pm 17$ and $192 \pm 10 \mathrm{mg} \mathrm{kg}^{-1}$ for steps $1-4$, respectively, in the wet-dry treatment, and $163 \pm 3,222 \pm 4$, $217 \pm 2.5$ and $214 \pm 6 \mathrm{mg} \mathrm{kg}^{-1}$ in the continuously wet treatment. The mass loss of DOC upon reaction with JRB soil was $248 \pm 19,257 \pm 1,197 \pm 5$ and $200 \pm 12 \mathrm{mg} \mathrm{kg}^{-1}$ for steps $1-4$, respectively, in the wet-dry treatment, and $256 \pm 7$, $236 \pm 26,176 \pm 44$ and $208 \pm 2 \mathrm{mg} \mathrm{kg}^{-1}$ in the continuously wet treatment. Hence, the mean fraction of $\mathrm{OC}$ removed from DOM solution was $58 \pm 5 \%$ (SD) after each reaction step with JRB soil, and OC uptake values were not significantly different between the continuously wet and wet-dry treatments. In the SCM soil, the mean fraction of OC removed was $41 \pm 4 \%$ of the total after each reaction step in the wetdry treatment. In contrast to the other three treatments, the continually wet SCM treatment indicated increasing amounts of OC removed in each step, with $39 \pm 0.8 \%$ in the first step, $48 \pm 1 \%$ in the second and $56 \pm 1 \%$ in the third and fourth steps (Fig. 1). At the end of four reaction steps the TOC of JRB soils increased from $1700 \pm 74 \mathrm{mg} \mathrm{OC} \mathrm{kg}^{-1}$ for the unreacted soil to $2750 \pm 87$ and $2840 \pm 99 \mathrm{mg} \mathrm{OC} \mathrm{kg}^{-1}$ for the wet-dry and continuously wet treatments, respectively (Fig. 1). For the JRB soil, increases in solid-phase OC were not significantly different (Student $t$ test, $p>0.95$ ) from the cumulative amounts of DOC removed from reacted solutions $\left(902 \pm 26\right.$ and $876 \pm 34 \mathrm{mg} \mathrm{OC} \mathrm{kg}^{-1}$ for wet- 

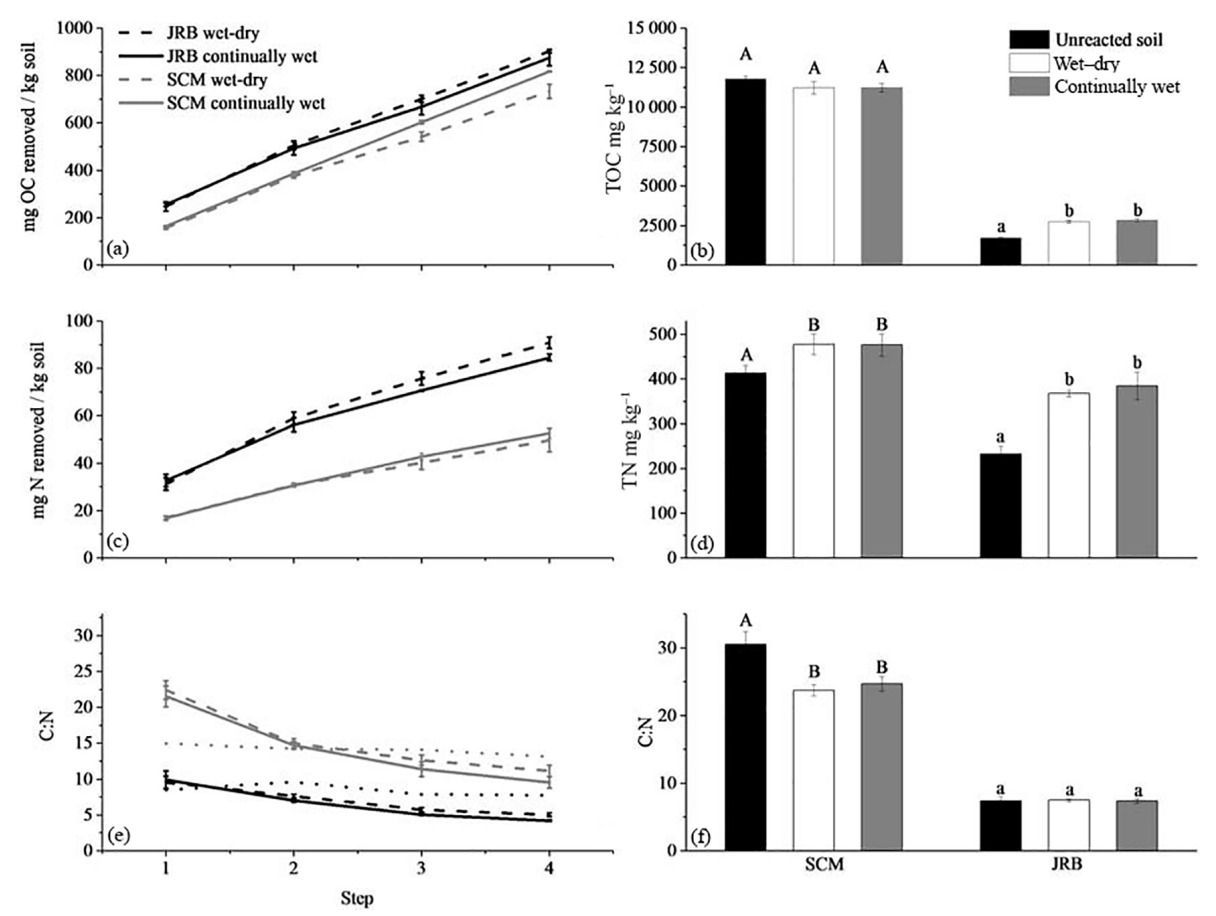

Figure 1. The organic carbon $(\mathbf{a}, \mathbf{b})$, nitrogen $(\mathbf{c}, \mathbf{d})$ and $\mathrm{C}: \mathrm{N}(\mathbf{e}, \mathbf{f})$, for equilibrated solutions $(\mathbf{a}, \mathbf{c}, \mathbf{e})$ and solid phases after four reaction steps $(\mathbf{b}, \mathbf{d}, \mathbf{f})$. Values for equilibrated solution OC and $\mathrm{N}$ represent cumulative removal from solution per soil mass. Dashed lines in OC and $\mathrm{N}$ plots show continuously wet treatments, dotted lines in the $\mathrm{C}: \mathrm{N}$ plot represent values of unreacted DOM solutions, error bars are the standard deviation and letters indicate significant difference (ANOVA and Tukey's HSD $p<0.05$ ) from unreacted control.

dry and continuously wet treatments, respectively) and represent a $60 \%$ increase in soil TOC. Conversely, for the SCM soil, despite comparable cumulative losses from solution ( $733 \pm 29$ and $817 \pm 2 \mathrm{mg} \mathrm{OC} \mathrm{kg}^{-1}$ for wet-dry and continuously wet treatments, respectively), solid-phase analyses indicated that the OC content of the reacted SCM (11 $200 \pm 380$ and $11200 \pm 290 \mathrm{mg} \mathrm{OC} \mathrm{kg}^{-1}$ soil for wetdry and continuously wet treatments, respectively) soils were effectively unchanged relative to the unreacted control $\left(11800 \pm 180 \mathrm{mg} \mathrm{OC} \mathrm{kg}^{-1}\right)$. We then tested for differences between the mean change in $\mathrm{OC}$ in the reacted soils and the mean amount of OC removed from solution using the Student $t$ test. Results demonstrate a significant mass loss of OC in the SCM soil $(p \leq 0.05)$, amounting to $1370 \pm 840$ and $1440 \pm 680 \mathrm{mg} \mathrm{OC} \mathrm{kg}^{-1}$ soil (for wet-dry and continuously wet treatments, respectively). These values represents $11 \pm 7$ and $11 \pm 5 \%$ of the total carbon in the wet-dry and continually wet systems.

Patterns in the removal of total $\mathrm{N}$ from the DOM solutions showed similar trends for both soils. In the first two wet-dry steps, a higher proportion of TN was removed from the solution (65-70 and 50-66\% for SCM and JRB soils, respectively) than in the third and fourth steps (31-44\% for both soils). The measured increase in soil TN by the end of the experiment were 63 and $143 \mathrm{mg} \mathrm{N} \mathrm{kg} \mathrm{soil}{ }^{-1}$ for SCM and JRB soils, respectively. These values are slightly higher than the sum of TN removed from the solution ( 51 and $88 \mathrm{mg} \mathrm{N} \mathrm{kg}$ soil $^{-1}$ for SCM and JRB soils, respectively; Fig. 1).

The $\mathrm{C}: \mathrm{N}$ ratio for all reacted DOM solutions decreased from step 1 to step 4, indicating preferential loss of $\mathrm{C}$ from solution, with no significant difference between the continually wet and wet-dry treatments. However, after the first reaction with the SCM soil, the $\mathrm{C}: \mathrm{N}$ ratio was $22.0 \pm 1.3$, which was higher than the unreacted DOM $(14.1 \pm 0.8)$. It is important to note that DOM extracted from unreacted soil had a $\mathrm{C}: \mathrm{N}$ ratio of $23.7 \pm 0.9$, and $\mathrm{C}: \mathrm{N}$ of DOM decreased during the sequential reaction steps. After the fourth reaction step, ratios of $11.1 \pm 0.8$ and $9.6 \pm 0.8$ were observed for the wet-dry and the continually wet treatments, respectively. The $\mathrm{C}: \mathrm{N}$ of the reacted DOM solution with JRB soil decreased, from $10 \pm 1.0$ after the first reaction step to $4.6 \pm 0.5$ after the fourth reaction step. The $\mathrm{C}: \mathrm{N}$ ratio of unreacted DOM solution was $8.4 \pm 0.8$. The overall change in soil $\mathrm{C}: \mathrm{N}$ ratio was evaluated by the differences between unreacted soil and soils reacted four times with DOM solutions (Fig. 1). Reacted SCM soils had significantly lower C : N (24.2 \pm 1$)$ than unreacted SCM soil $(30.5 \pm 1.8)$. However, no change in $\mathrm{C}: \mathrm{N}$ was detected for reacted versus unreacted JRB soils.

\subsection{UV-Vis and fluorescence spectroscopy}

Reaction with subsoils altered spectroscopic properties of the litter-derived DOM solutions as reflected in UV-Vis 

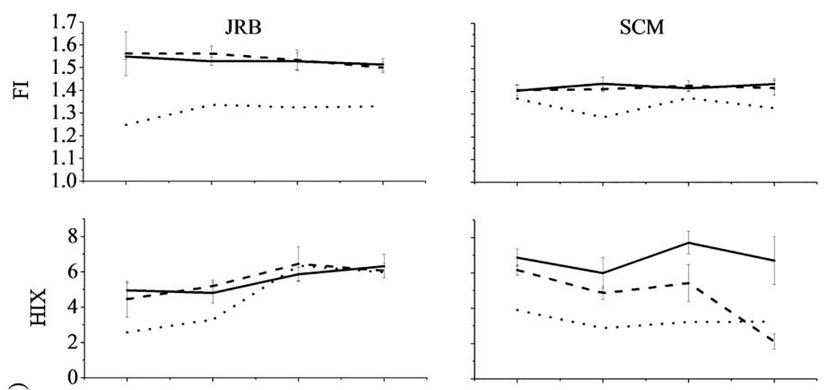

药 1000 - - - Wet-dry
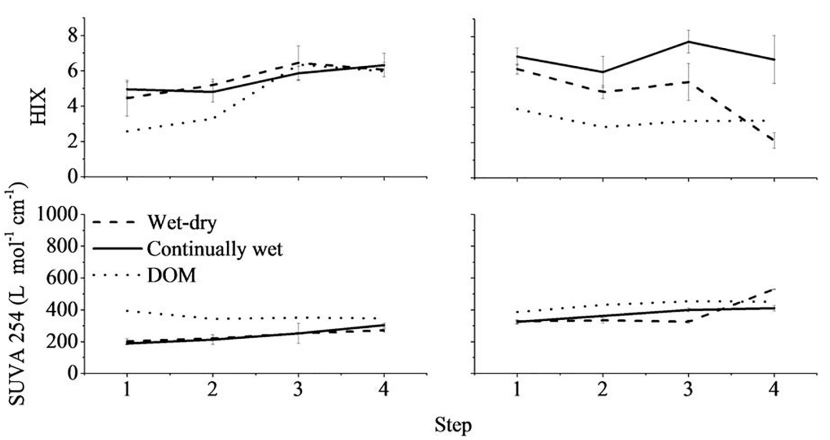

Figure 2. The fluorescence Index (FI), humification index (HIX) and specific UV absorbance at $245 \mathrm{~nm}\left(\mathrm{SUVA}_{254}\right)$, for equilibrated solutions reacted with JRB and SCM soils. The solid lines are wetdry series, dashed lines are continuously wet and dotted lines are unreacted DOM; error bars are the standard deviation.

$\left(\mathrm{SUVA}_{254}\right)$ and fluorescence indices (HIX and FI), and there was relatively little variation between continually wet and wet-dry treatments (Fig. 2). For both JRB and SCM the $\mathrm{SUVA}_{254}$ values of DOM decreased (relative to unreacted DOM) upon contact with soil (Fig. 2), with the exception of the fourth step in wet-dry treatment of SCM soil (Fig. 2). This effect of contact with soil on $\mathrm{SUVA}_{254}$ was larger for JRB than SCM, although it decreased with progressive reaction steps even for JRB soils from ca. $200 \mathrm{~L} \mathrm{~mol}^{-1} \mathrm{~cm}^{-1}$ in the first step to ca. $50 \mathrm{~L} \mathrm{~mol}^{-1} \mathrm{~cm}^{-1}$ by the fourth step. High SUVA $254\left(905 \pm 35 \mathrm{~L} \mathrm{~mol}^{-1} \mathrm{~cm}^{-1}\right)$ was measured for DOM extracted from unreacted JRB soil (Table 1). We note that $\mathrm{SUVA}_{254}$ values of unreacted DOM also decreased between the first $\left(393 \mathrm{~L} \mathrm{~mol}^{-1} \mathrm{~cm}^{-1}\right)$ and subsequent steps $\left(\sim 350 \mathrm{~L} \mathrm{~mol}^{-1} \mathrm{~cm}^{-1}\right)$, indicating some alteration of DOM chromophores in the stock DOM solution during the experiment. Although this was a small change relative to soil reaction effects, alteration was also evident in the HIX of unreacted JRB DOM. Therefore, treatment effects (continuously wet and wet-dry) were evaluated on the basis of differences between reacted and unreacted solutions for the same reaction step. The effect of reaction with soil on $\mathrm{SUVA}_{254}$ values were less pronounced for SCM relative to JRB soils. In the wet-dry treatments of SCM soil, SUVA $_{254}$ values of the first three steps were generally consistent at ca. $330 \pm 13\left(\mathrm{~L} \mathrm{~mol}^{-1} \mathrm{~cm}^{-1}\right)$, and in the fourth step the $\mathrm{SUVA}_{254}$ increased to $530 \pm 2\left(\mathrm{~L} \mathrm{~mol}^{-1} \mathrm{~cm}^{-1}\right)$. Conversely, $\mathrm{SUVA}_{254}$ values increased slightly over the course of the experiment from $324 \pm 10$ to $410 \pm 16 \mathrm{~L} \mathrm{~mol}^{-1} \mathrm{~cm}^{-1}$ for the continually wet SCM treatment.

Humification index (HIX) values for the reacted DOM were generally higher or similar to the unreacted DOM
(Fig. 2). As with the $\mathrm{SUVA}_{254}$ index, the fourth step of SCM wet-dry treatment was the exception (Fig. 2), giving a lower HIX for reacted compared to unreacted DOM. The HIX values for DOM that reacted with JRB soil were similar for continually wet and wet-dry treatments. Conversely, with SCM soil, values for the wet-dry treatments were lower than for continually wet treatments. The relative differences between reacted and unreacted DOM were lower for the JRB system than for the SCM system. For both JRB and SCM soils, higher fluorescence index (FI) values were observed for reacted relative to unreacted DOM (Fig. 2) whereas wet-dry versus wet-only treatment effects were negligible. For JRB, FI values increased from $1.31 \pm 0.04$ (unreacted DOM) to $1.53 \pm 0.04$, whereas corresponding values for SCM were $1.34 \pm 0.04$ and $1.42 \pm 0.02$, respectively. All FI values are in close agreement with the value of DOM associated with predominantly plant material (ca. 1.4), as opposed to microbialderived DOM (ca. 1.9; McKnight et al., 2001).

\subsection{FTIR}

Transmission FTIR spectra of reacted and unreacted DOM for the JRB and SCM systems are shown in Figs. 3 and 4, respectively. The most prevalent peaks in the spectra were associated with amide I and II (1636 and $1560 \mathrm{~cm}^{-1}$, respectively), carboxylate (asymmetric and symmetric stretches at 1592 and $1417 \mathrm{~cm}^{-1}$, respectively), alkyl $\left(\mathrm{CH}_{2}\right.$ and $\mathrm{CH}_{3}$ bending vibrations at 1455 and $1380 \mathrm{~cm}^{-1}$, respectively) and aromatic moieties $\left(\mathrm{C}=\mathrm{C}\right.$ ring vibration at $1500 \mathrm{~cm}^{-1}$, phenol $\mathrm{O}-\mathrm{H}$ bend $\left.1370 \mathrm{~cm}^{-1}\right)$ and O-alkyl $\left(\mathrm{CO}^{-}\right.$stretch at $1030-1150 \mathrm{~cm}^{-1}$ ).

For JRB soil, the first reaction step in both continually wet and wet-dry treatments was accompanied by a decrease in peak intensities of carboxylate $\left(1592\right.$ and $\left.1417 \mathrm{~cm}^{-1}\right)$ and amide (1636 and 1560) relative to O-alkyl (1150$\left.1030 \mathrm{~cm}^{-1}\right)$. Additionally, primary alcohol $\left(1035 \mathrm{~cm}^{-1}\right)$ peak intensity decreased relative to secondary alcohol $\left(1100 \mathrm{~cm}^{-1}\right)$. This trend persisted in the second step with JRB soil for both treatments, although the pattern was less pronounced and differed by treatment. Specifically, the wetdry treatment showed a larger decrease in the asymmetric carboxylate stretch $\left(1592 \mathrm{~cm}^{-1}\right)$, whereas the continuously wet treatment showed a larger decrease in the amide I peak $\left(1636 \mathrm{~cm}^{-1}\right)$. In the third step, the decrease in amide and carboxyl peaks relative to O-alkyl was not as pronounced for the wet-dry treatment as it was in the continually wet treatment. Finally, in the fourth step of the wet-dry system, a pronounced decrease in amide and carboxyl peaks relative to O-alkyl was again observed, whereas it was not in the continually wet treatment (Fig. 3).

Figure 4 shows the spectra of reacted and unreacted DOM in the SCM system. The SCM DOM spectra show similar peaks as the JRB with the addition of carboxyl $(\mathrm{C}=\mathrm{O}$ stretch at $\left.1720 \mathrm{~cm}^{-1}\right)$ and ester $\left(\mathrm{C}=\mathrm{O}\right.$ stretch $1770 \mathrm{~cm}^{-1}$ and $\mathrm{C}-\mathrm{O}$ stretch $1265 \mathrm{~cm}^{-1}$ ). Similar to the JRB system, after reaction 
(a) Continually wet

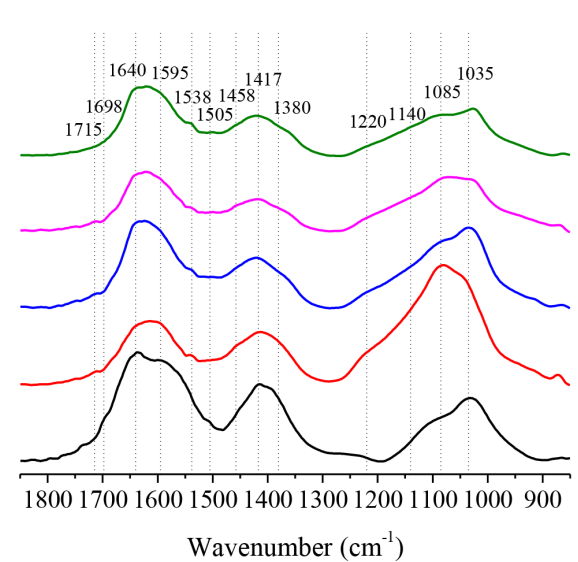

(b) Wet-dry

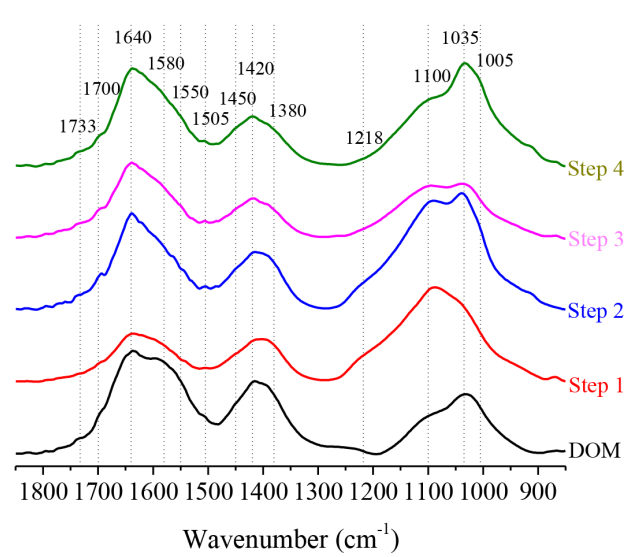

Figure 3. Transmission FTIR spectra of the dried DOM solution reacted with JRB soils from steps 1 to 4 for continuously wet (a) and wet-dry cycles (b) and the unreacted JRB DOM solution (bottom black line). For color rendering of this image please refer to the online version.

(a) Continually wet

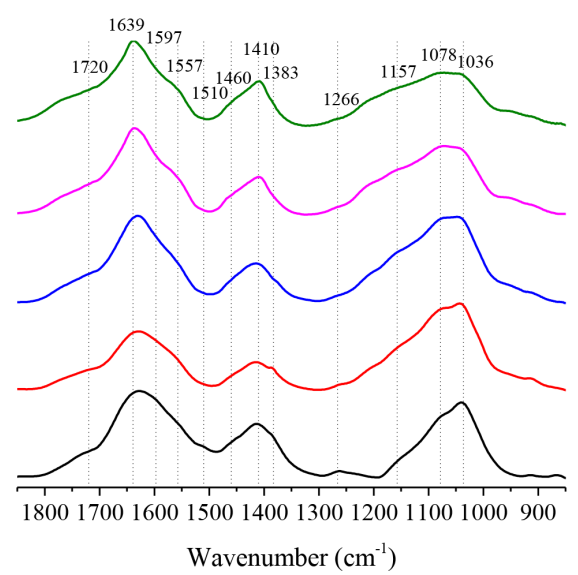

(b) Wet-dry

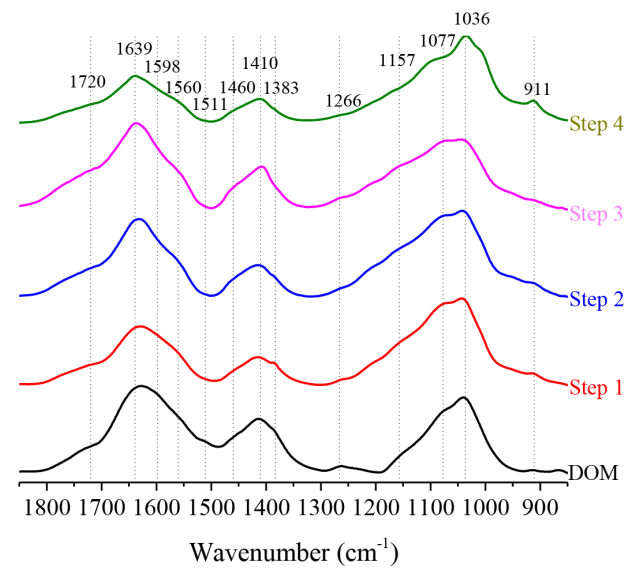

Figure 4. Transmission FTIR spectra of the dried DOM solution reacted with SCM soils from steps 1 to 4 for continuously wet (a) and wet-dry cycles (b) and the unreacted SCM DOM solution (bottom line). For color rendering of this image please refer to the online version.

with soil, the peaks associated with carboxyl, carboxylate and amide decreased relative to the O-alkyl peaks, and this trend was more pronounced in the first step than in the subsequent steps. Similar to the JRB system, in the fourth step of the wet-dry treatment, a pronounced decrease in carboxyl, carboxylate and amide peaks was again observed relative to the O-alkyl peaks.

\subsection{STXM-NEXAFS}

Given limitations in beam time, synchrotron analyses were focused on the JRB soil because it showed larger OC accumulation over the course of the experiment. Scanning transmission X-ray microscopy (STXM) images of C, Fe and Ca obtained for the isolated fine fraction of JRB soils reacted four times with DOM in wet-dry and continually wet treat- ments are shown in Figs. 5 and 6, respectively. The OC signal was observed over all particle surfaces, from continually wet and wet-dry treatments after four reaction steps. Locations of higher $\mathrm{Fe}$ and $\mathrm{Ca}$ content were observed for both treatments. Near-edge X-ray absorption fine structure (NEXAFS) spectra extracted from $\mathrm{C}, \mathrm{Ca}$ and $\mathrm{Fe}$-rich regions of interest (ROI) of the STXM maps and C NEXAFS spectra of bulk unreacted soil and DOM are included in Figs. 5 and 6 . Spectra of the unreacted DOM consist of peaks representing aromatic $\left(1 \mathrm{~s} \rightarrow \pi^{*}\right.$ at $\left.285.1 \mathrm{eV}\right)$, alkyl $\left(1 \mathrm{~s} \rightarrow 3 p / \sigma^{*}\right.$ at $287.5 \mathrm{eV})$, amide $\left(1 \mathrm{~s} \rightarrow \pi^{*}\right.$ at $\left.288 \mathrm{eV}\right)$, carboxyl $\left(1 \mathrm{~s} \rightarrow \pi^{*}\right.$ at 288.5 and $290 \mathrm{eV})$ and O-alkyl $\left(1 \mathrm{~s} \rightarrow \pi^{*}\right.$ at $\left.289.5 \mathrm{eV}\right)$ moieties. The C NEXAFS spectra of unreacted soil show no strong peaks of amide, carboxyl and O-alkyl, similar to the unreacted DOM spectra. However, after four steps of reaction with DOM, soil from both continually wet and wet-dry 

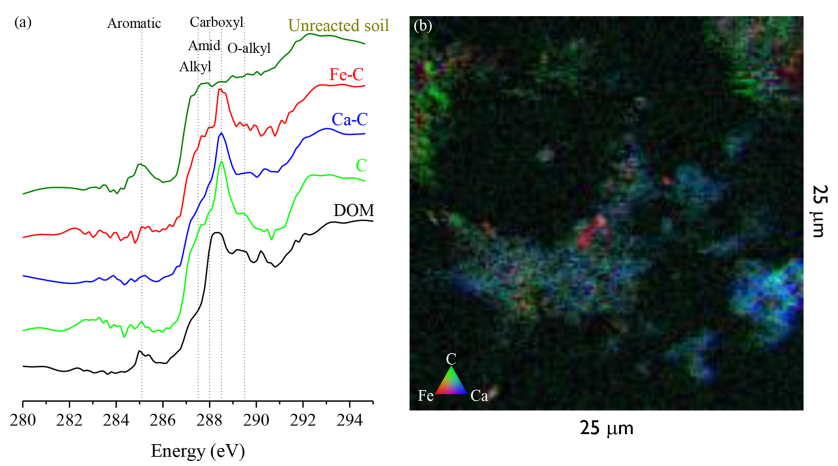

Figure 5. JRB soil reacted with DOM under wet-dry cycling. (a) C NEXAFS spectra extracted from C, Ca and Fe regions of STXM map. Spectra of unreacted soil (top) and DOM solution (bottom) are presented. Dashed vertical lines point out $\mathrm{C}$ species. (b) Tri-colored STXM map of fine fraction from JRB soil reacted four times with DOM under wet-dry cycling; Fe (red), Ca (blue) and C (green). Image size $25 \mu \mathrm{m} \times 25 \mu \mathrm{m}$. For color rendering of this image please refer to the online version.

treatments exhibited greatly enhanced carboxyl and O-alkyl peaks relative to the unreacted soil. In the wet-dry treatment, the aromatic peak was absent. The O-alkyl peak was more pronounced for the continually wet than for the wetdry treatment. Additionally, the amide peak was suppressed in the reacted soil compared to the unreacted DOM, and for the wet-dry treatment this peak was absent and was not included in the fitted spectra (Supplement). The C NEXAFS spectra of Ca- and Fe-enriched ROIs are similar to the average whole image spectra. However in the Ca ROI, the carboxyl peak intensity was enhanced relative to Fe ROI and the averaged whole image spectra. This carboxyl enhancement, which was absent in the unreacted soil, was most pronounced in the wet-dry treatment.

Variations in the C NEXAFS spectra of the reacted soils following each reaction step are displayed in Fig. 7. After the first reaction step, intensities of the carboxyl and O-alkyl peaks were relatively increased. For the continually wet treatment, spectra collected following the second and third steps show an increase in alkyl and O-alkyl peaks, whereas this trend was less evident in the wet-dry treatment.

\section{Discussion}

Specific surface area (SSA) and OC content are dominant factors controlling sorption of DOM to soil. For comparable mineralogy, higher SSA tends to increase DOM sorption, while higher solid-phase OC content suppresses it (Kaiser et al., 1997; Oren and Chefetz, 2012b). In addition, solution chemistry can control DOM-soil interactions. For example, low $\mathrm{pH}$ can neutralize weakly acidic OM functionalities, thereby decreasing electrostatic repulsion from negatively charged surfaces, whereas bivalent cations such as $\mathrm{Ca}^{2+}$ can
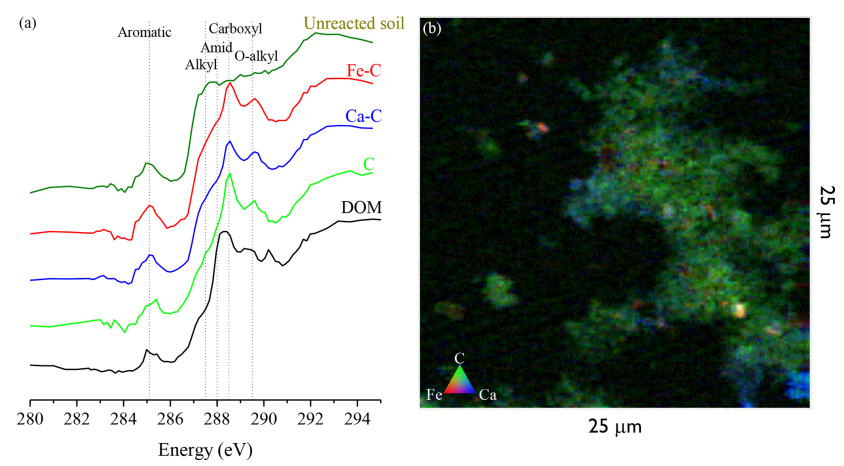

Figure 6. JRB soil reacted with DOM under continuously wet conditions. (a) C NEXAFS spectra extracted from $\mathrm{C}, \mathrm{Ca}$ and $\mathrm{Fe}$ regions of STXM map. Spectra of unreacted soil (top) and DOM solution (bottom) are presented. Dashed vertical lines point out $\mathrm{C}$ species. (b) Tri-colored STXM map of fine fraction from JRB soil reacted four times with DOM during the continuously wet treatment. Fe (red), Ca (blue) and C (green). Image size $25 \mu \mathrm{m} \times 25 \mu \mathrm{m}$. For color rendering of this image please refer to the online version.
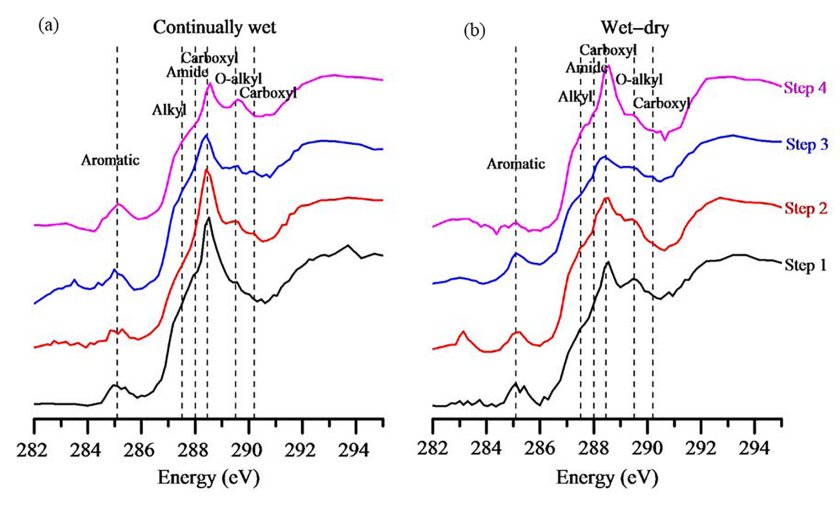

Figure 7. C NEXAFS extracted from $\mathrm{C}$ (red in Fig. 6) regions of STXM map for the second step of the continuously wet treatment (a) and from all four steps of the wet-dry treatment (b). For color rendering of this image please refer to the online version.

form bridging complexes between negatively charged surface and DOM sites (e.g., Setia et al., 2013). Further, the presence of polyvalent metal cations in solution can promote precipitation of (meta-)stable OM-metal complexes (Kleber et al., 2014). Gradual drying of pore water changes the ionic strength of the solution, and can potentially promote interactions with metal cations in solution and at organo-mineral surfaces. In the current study, in spite of differences in soil constituents and DOM compositions deriving from the two distinct CZO sites, similar amounts of DOM were removed from solution with both JRB and SCM soils. The fact that OC did not accumulate in the solid-phase SCM soil despite significant removal from solution suggests that decomposition and mineralization are dominant factors indicated in the removal of OC from the reacted SCM DOM solutions. Since microbial activity was not suppressed in this study, an 
active microbial community was presumably present in the soils. Therefore, addition of labile OC in the form of DOM may have resulted in microbial growth and biotransformation of pre-existing soil OC. Indeed, the pronounced decrease in $\mathrm{C}: \mathrm{N}$ ratio of the reacted soil is consistent with microbial transformation of organic matter (German et al., 2011). Higher HIX for all SCM reacted samples, with the exception of the last step in the wet-dry treatment, further support OM transformation. Enhanced mineralization in the SCM relative to JRB soil may be related to its substantially higher native OC content (Table 1), which would preclude surface stabilizing interactions (Kaiser et al., 1997; Oren and Chefetz, 2012b). Moreover, higher OC content makes the SCM soil more susceptible to the priming effect of the added labile OC as DOM (Blagodatsky et al., 2010). The relatively lower HIX value for the last step of wet-dry treatment coincides with higher SUVA 254 . Since SUVA 254 index is correlated with sample aromaticity (Weishaar et al., 2003), an increase in the aromatic peak in the FTIR spectra was expected. However, FTIR spectra show a relative increase in O-alkyl rather than the aromatic vibrations. It is possible that the relative decrease observed in the 1550 to $1700 \mathrm{~cm}^{-1}$ region of the FTIR spectra is mainly due to a decrease in carboxyl associated peaks rather than increased aromaticity. It is unclear if the removed fraction was exchanged with previously adsorbed OM or preferentially decomposed in the solution. Additional study using isotopically labeled material may provide additional information regarding decomposition and exchange reactions in similar systems.

Conversely, significant DOM or soil organic matter decomposition was not observed for the JRB soil experiments, as evidenced from the $\mathrm{C}$ mass balance. Therefore, changes in reacted DOM composition can be attributed to preferential adsorption and exchange reactions. The increased FI value of the reacted DOM further suggests preferential adsorption of plant-relative OM over microbial-derived OM. The slight decrease in $\mathrm{SUVA}_{254}$ values is also consistent with this observation, since polyphenols derived from lignin account for most of the aromaticity in DOM.

Spectra from C-NEXAFS obtained for the JRB soil fine fraction corroborate the solution data obtained by FTIR. A pronounced increase in the carboxyl peak $(288.5 \mathrm{eV})$ after the first reaction step (Fig. 7) is consistent with the decreased intensity of carboxyl in the reacted DOM solutions (Fig. 3). NEXAFS spectra collected after the second and third steps of both treatments show additional increases in the O-alkyl $(289.5 \mathrm{eV})$ and alkyl $(287.5 \mathrm{eV})$ that corroborate the relative decrease in FTIR peak intensities for these functionalities. The fact that the NEXAFS of the reacted JRB soils clearly shows a relative increase in the carboxyl peak from the third to the fourth step in the wet-dry treatment (Fig. 7) suggests that preferential adsorption of the carboxylic component was facilitated by the pre-existing soil-DOM phases of the dried soil. Prior work has shown that soil drying may promote conformational changes in pre-adsorbed DOM that pro- motes preferential desorption of O-alkyl relative to further inner-sphere coordination of carboxyl components (Kang et al., 2008; Kang and Xing, 2007). Additional support for the formation of inner-sphere carboxyl complexes is from the higher preferential adsorption of carboxyl over amide as observed in FTIR spectra of wet-dry compared to continuously wet treatments (Fig. 3).

Due to the heterogeneous composition of soil surfaces and DOM, spatial fractionation of the adsorbed OC moieties was expected. Figures 5 and 6 show that in both wet-dry and continuously wet treatments, regions containing higher content of $\mathrm{Fe}$ and $\mathrm{Ca}$ can be distinguished. Interestingly, the C NEXAFS spectra of these distinct locations are generally similar. It is important to note that low Fe spectral signals were detected over all of the particle surfaces images with STXM. This observation contradicts our initial hypothesis, and previous observations (Chorover and Amistadi, 2001; Kaiser et al., 1997; Oren and Chefetz, 2012b; Vazquez-Ortega et al., 2014) that iron (oxy)hydroxides will preferentially adsorb carboxyl-containing moieties. These results suggest that weathered particle surfaces, potentially already coated with a thin layer of metal $(\mathrm{Fe})$ oxides and co-associated organic matter, may smear out what might otherwise be observed as a spatial fractionation at this scale (nanometers).

However, close inspection of the $\mathrm{C}$ spectra extracted from $\mathrm{Fe}$ - and $\mathrm{Ca}$-enriched zones and whole particle regions reveal that in samples treated with wet-dry steps, the amplitude of the carboxyl peak shows a relative increase preferentially in the Ca-enriched regions (Fig. 5 and Supplement). This finding suggests that cation bridging interactions are pronounced in stabilizing the carboxyl component in the studied soil. It is important to note that the solution $\mathrm{pH}$ was close to 7, and therefore deprotonated carboxylate species were predominant in the suspension. Regions of high $\mathrm{Ca}$ are likely associated with charged aluminosilicate surfaces hosting exchangeable cations. The enhancement effect of drying on $\mathrm{Ca}$-carboxylate complex formation can be related to the tendency of the $\mathrm{Ca}^{2+}$ hydration shell to become more acidic upon drying (Sposito, 1984). As water molecules are gradually removed during air drying, polarizing forces of the $\mathrm{Ca}^{2+}$ cation increases, enhancing the tendency of hydration water to donate protons (Dowding et al., 2005). Therefore, upon drying, protonation of the carboxylate functionality is expected. Protonation of carboxylate decreases the electrostatic repulsion from negatively charged clay surfaces and increases the overall interaction with clays. It is important to note that our studied soils are predominantly composed of silicate and aluminosilicate minerals and are relatively depleted in crystalline and short-range-order metal oxides.

\section{Conclusions}

Results of this study show that wet-dry cycles affect interactions between DOM and subsurface soils, in this case 
by enhancing the interactions between carboxyl functional group and soil surfaces. Interactions of these functionalities were dominated by $\mathrm{Ca}^{2+}$ bridging to soil surfaces. The data also demonstrate that nanoscale spatial fractionation of DOM on soil organo-mineral surfaces was diminished relative to what might be inferred from previous observations pertaining to DOM fractionation on specimen mineral phases. This is likely due to the heterogeneous composition of the weathered soil surfaces and passivation of the underlying mineralogy by metal oxide and OM films. Expanding the experiment to include soils with a higher proportion of short-range-order (oxy)hydroxides may result in more pronounced nanoscale spatial fractionation of DOM, but that is unknown at present. Fractionation of DOM in solution under wet-dry conditions for a soil that presented measurable decomposition of the DOM (SCM) was similar to that for a soil that did not show any detectable decomposition (JRB).

This study provides direct evidence of the role of wet-dry cycles in the sorption reactions of DOM to a complex soil matrix. In the soil environment, where wet-dry cycles occur at variable frequencies from site to site and along the soil profile, different interactions between DOM and soil surfaces are expected. This wet-dry effect can partially explain the observation that carbohydrates predominate in subsoil horizons, where soil is less subjected to drying, whereas aromatic and carboxylic compounds are more prevalent in top soils, where wet-dry cycles are more frequent (Kaiser and Kalbitz, 2012). Our findings demonstrate the need to consider the effect of wet-dry cycles in studying the interactions between DOM and soil surfaces.

Data availability. STXM data and FITR available via the following link:
tra are avec-
https://doi.org/10.4211/hs.eb20c1fa74ad44a2a51834985dbf4481
(Olshansky, 2018).

\section{The Supplement related to this article is available online at https://doi.org/10.5194/bg-15-821-2018-supplement.}

Competing interests. The authors declare that they have no conflict of interest.

Acknowledgements. This research was funded by the Binational Agricultural Research and Development (BARD) program, postdoctoral fellowship to Yaniv Olshansky grant no. FI-534-2015, and the National Science Foundation, grant no. EAR 13-31408, which supports the Catalina-Jemez Critical Zone Observatory. The STXM analysis described in this paper was performed at the Canadian Light Source beamline 10ID-1, which is supported by the Canadian Foundation for Innovation, Natural Sciences and Engineering Research Council of Canada, the University of Saskatchewan, the
Government of Saskatchewan, Western Economic Diversification Canada, the National Research Council Canada, and the Canadian Institutes of Health Research. Thanks to Mary Kay Amistadi, Rachel Nadine Burnett and Prakash Dhakal for assistance with analysis.

Edited by: Michael Weintraub

Reviewed by: two anonymous referees

\section{References}

Abdulla, H. A. N., Minor, E. C., Dias, R. F., and Hatcher, P. G.: Changes in the compound classes of dissolved organic matter along an estuarine transect: A study using FTIR and 13C NMR, Geochim. Cosmochim. Acta, 74, 3815-3838, 2010.

Blagodatsky, S., Blagodatskaya, E., Yuyukina, T., and Kuzyakov, Y.: Model of apparent and real priming effects: Linking microbial activity with soil organic matter decomposition, Soil Biol. Biochem., 42, 1275-1283, 2010.

Chen, C., Dynes, J. J., Wang, J., and Sparks, D. L.: Properties of Fe-Organic Matter Associations via Coprecipitation versus Adsorption, Environ. Sci. Technol., 48, 13751-13759, 2014a.

Chen, C., Dynes, J. J., Wang, J., Karunakaran, C., and Sparks, D. L.: Soft X-ray spectromicroscopy study of mineral-organic matter associations in pasture soil clay fractions, Environ. Sci. Technol., 48, 6678-6686, 2014b.

Chorover, J. and Amistadi, M. K.: Reaction of forest floor organic matter at goethite, birnessite and smectite surfaces, Geochim. Cosmochim. Acta, 65, 95-109, 2001.

Chorover, J., Kretzschmar, R., Garica-Pichel, F., and Sparks, D. L.: Soil biogeochemicial processes within the critical zone, Elements, 3, 321-326, 2007.

Chorover, J., Troch, P. A., Rasmussen, C., Brooks, P. D., Pelletier, J. D., Breshears, D. D., Huxman, T. E., Kurc, S. A., Lohse, K. A., McIntosh, J. C., Meixner, T., Schaap, M. G., Litvak, M. E., Perdrial, J., Harpold, A., and Durcik, M.: How Water, Carbon, and Energy Drive Critical Zone Evolution: The Jemez-Santa Catalina Critical Zone Observatory, Vadose Zone J., 10, 884899, 2011.

Cody, G. D., Ade, H., Wirick, S., Mitchell, G. D., and Davis, A.: Determination of chemical-structural changes in vitrinite accompanying luminescence alteration using C-NEXAFS analysis, Org. Geochem., 28, 441-455, 1998.

Cody, G. D., Ade, H., Alexander, C. M. O. D., Araki, T., Butterworth, A., Fleckenstein, H., Flynn, G., Gilles, M. K., Jacobsen, C., Kilcoyne, A. L. D., Messenger, K., Sandford, S. A., Tyliszczak, T., Westphal, A. J., Wirick, S., and Yabuta, H.: Quantitative organic and light-element analysis of comet 81P/Wild 2 particles using C-, N-, and O- $\mu$-XANES, Meteorit. Planet. Sci., 43, 353-365, 2008.

Dowding, C. E., Borda, M. J., Fey, M. V., and Sparks, D. L.: A new method for gaining insight into the chemistry of drying mineral surfaces using ATR-FTIR, J. Colloid Interface Sci., 292, 148151, 2005.

Eusterhues, K., Rennert, T., Knicker, H., Kogel-Knabner, I., Totsche, K. U., and Schwertmann, U.: Fractionation of organic matter due to reaction with ferrihydrite: Coprecipitation versus adsorption, Environ. Sci. Technol., 45, 527-533, 2011. 
Eusterhues, K., Neidhardt, J., Hädrich, A., Küsel, K., and Totsche, K. U.: Biodegradation of ferrihydrite-associated organic matter, Biogeochemistry, 119, 45-50, 2014.

Fontaine, S., Barot, S., Barré, P., Bdioui, N., Mary, B., and Rumpel, C.: Stability of organic carbon in deep soil layers controlled by fresh carbon supply, Nature, 450, 277-280, 2007.

German, D. P., Weintraub, M. N., Grandy, A. S., Lauber, C. L., Rinkes, Z. L., and Allison, S. D.: Optimization of hydrolytic and oxidative enzyme methods for ecosystem studies, Soil Biol. Biochem., 43, 1387-1397, 2011.

Gu, B., Schmitt, J., Chen, Z., Liang, L., and McCarthy, J. F.: Adsorption and desorption of natural organic matter on iron oxide: mechanisms and models, Environ. Sci. Technol., 28, 38-46, 1994.

Guo, M. and Chorover, J.: Transport and fractionation of dissolved organic matter in soil columns, Soil Sci., 168, 108-118, 2003.

Hitchcock, A., Hitchcock, P., Jacobsen, C., Zimba, C., Loo, B., Rotenberg, E., Denlinger, J., and Kneedler, R.: aXis 2000Analysis of X-ray Images and Spectra, available at: http:// unicorn.mcmaster.ca/aXis2000.html (last access: June 2016), 2012.

Kaiser, K. and Kalbitz, K.: Cycling downwards - dissolved organic matter in soils, Soil Biol. Biochem., 52, 29-32, 2012.

Kaiser, K., Guggenberger, G., Haumaier, L., and Zech, W.: Dissolved organic matter sorption on subsoils and minerals studied by $13 \mathrm{C}-\mathrm{NMR}$ and DRIFT spectroscopy, Eur. J. Soil Sci., 48, 301-310, 1997.

Kalbitz, K., Solinger, S., Park, J.-H., Michalzik, B., and Matzner, E.: Controls on the dynamics of dissolved organic matter in soils: A review, Soil Sci., 165, 277-304, 2000.

Kang, S. and Xing, B.: Adsorption of dicarboxylic acids by clay minerals as examined by in situ ATR-FTIR and ex situ DRIFT, Langmuir, 23, 7024-7031, 2007.

Kang, S., Amarasiriwardena, D., and Xing, B.: Effect of dehydration on dicarboxylic acid coordination at goethite/water interface, Colloid. Surface A, 318, 275-284, 2008.

Kleber, M., Sollins, P., and Sutton, R. K.: A conceptual model of organo-mineral interactions in soils: self-assembly of organic molecular fragments into zonal structures on mineral surfaces, Biogeochemistry, 85, 9-24, 2007.

Kleber, M., Eusterhues, K., and Keiluweit, M.: Mineral-Organic associations: formation, properties, and relevance in soil environments, edited by: Sparks, D., Adv. Agron., 130, 1-140, 2014.

Lutzow, M. V., Kogel-Knabner, I., Ekschmitt, K., Matzner, E., Guggenberger, G., Marschner, B., and Flessa, H.: Stabilization of organic matter in temperate soils: mechanisms and their relevance under different soil conditions - a review, Eur. J. Soil Sci., 57, 426-445, 2006.

Mangiafico, S.: Summary and Analysis of Extension Program Evaluation in R, version 1.10.0, available at: http://rcompanion.org/ handbook/, last access: December, 2016.

Mayo, D. W., Miller, F. A., and Hannah, R. W.: Course Notes on the Interpretation of Infrared and Raman Spectra, John Wiley \& Sons, Inc., Hoboken, NJ, USA, 2004.

McKnight, D. M., Boyer, E. W., Westerhoff, P. K., Doran, P. T., Kulbe, T., and Anderson, D. T.: Spectroflourometric characterization of dissolved organic matter for indication of precursor organic material and aromaticity, L\&O, 46, 38-48, 2001.
Miller, A. E., Schimel, J. P., Meixner, T., Sickman, J. O., and Melack, J. M.: Episodic rewetting enhances carbon and nitrogen release from chaparral soils, Soil Biol. Biochem., 37, 2195-2204, 2005.

Murphy, K. R., Stedmon, C. A., Graeber, D., and Bro, R.: Fluorescence spectroscopy and multi-way techniques. PARAFAC, Anal. Methods, 5, 6557, 2013.

Myneni, S. C.: Soft X-ray spectroscopy and spectromicroscopy studies of organic molecules in the environment, Rev. Mineral. Geochemistry, 49, 485-579, 2002.

Ohno, T.: Fluorescence inner-filtering correction for determining the humification index of dissolved organic matter, Environ. Sci. Technol., 36, 742-746, 2002.

Olshansky, Y., Polubesova, T., and Chefetz, B.: Reconstitution of cutin monomers on smectite surfaces?: adsorption and esterification, Geoderma, 232-234, 406-413, 2014

Olshansky, Y.: Wet-dry cycles impact DOM retention in subsurface soils, HydroShare, available at: https://doi.org/10.4211/hs.eb20c1fa74ad44a2a51834985dbf4481, 2018.

Omoike, A. and Chorover, J.: Spectroscopic study of extracellular polymeric substances from Bacillus subtilis: aqueous chemistry and adsorption effects, Biomacromolecules, 5, 1219-1230, 2004.

Oren, A. and Chefetz, B.: Sorptive and desorptive fractionation of dissolved organic matter by mineral soil matrices, J. Environ. Qual., 41, 526-533, 2012a.

Oren, A. and Chefetz, B.: Successive sorption-desorption cycles of dissolved organic matter in mineral soil matrices, Geoderma, 189-190, 108-115, 2012b.

Perdrial, J. N., McIntosh, J., Harpold, A., Brooks, P. D., ZapataRios, X., Ray, J., Meixner, T., Kanduc, T., Litvak, M., Troch, P. A., and Chorover, J.: Stream water carbon controls in seasonally snow-covered mountain catchments: impact of inter-annual variability of water fluxes, catchment aspect and seasonal processes, Biogeochemistry, 118, 273-290, 2014.

Polubesova, T. and Chefetz, B.: DOM-Affected Transformation of Contaminants on Mineral Surfaces: A Review, Crit. Rev. Environ. Sci. Technol., 44, 223-254, 2014.

Polubesova, T., Chen, Y., Navon, R., and Chefetz, B.: Interactions of hydrophobic fractions of dissolved organic matter with $\mathrm{Fe}\left({ }^{3+}\right)-$ and $\mathrm{Cu}^{2+}$ )-montmorillonite, Environ. Sci. Technol., 42, 47974803, 2008.

Ravel, B. and Newville, M.: ATHENA, ARTEMIS, HEPHAESTUS: Data analysis for X-ray absorption spectroscopy using IFEFFIT, J. Synchrotron Radiat., 12, 537-541, 2005.

Rumpel, C. and Kögel-Knabner, I.: Deep soil organic matter - a key but poorly understood component of terrestrial C cycle, Plant Soil, 338, 143-158, 2010.

Setia, R., Rengasmy, P., and Marschner, P.: Effect of exchangeable cation concentration on sorption and desorption of dissolved organic carbon in saline soils, Sci. Total Environ., 465, 226-232, 2013.

Socrates, G.: Infrared and Raman characteristic group frequencies: Tables and charts, 3rd Edn., John Wiley \& Sons, Ltd, Chichester, UK, 2004.

Soil Survey Staff: Keys to Soil Taxonomy, 11 Edn., USDA- Natural Resources Conservation Service, Washington, DC, 2010.

Sparks, D. L.: Methods of soil analysis, in: Part 3: chemical methods, Soil Science Society of America, Madison, WI, 1996. 
Sposito, G.: The structure of water near clay mineral surfaces, in The surface chemistry of soils, 47-77, Oxford University Press, New York, 1984.

Urquhart, S. G., Hitchcock, A. P., Smith, A. P., Ade, H., and Rightor, E. G.: Inner-Shell Excitation Spectroscopy of Polymer and Monomer Isomers of Dimethyl Phthalate, J. Phys. Chem. B, 101, 2267-2276, 1997.

USDA-NRCS: Soil survey geographic (SSURGO) database for Sandoval County area, New Mexico (Includes parts of Los Alamos and Rio Arriba Counties), Fort Worth, TX, 1999.

Vázquez-Ortega, A., Hernandez-Ruiz, S., Amistadi, M. K., Rasmussen, C., and Chorover, J.: Fractionation of Dissolved Organic Matter by (Oxy)Hydroxide-Coated Sands: Competitive Sorbate Displacement during Reactive Transport, Vadose Zone J., 13, 213, 2014.
Weishaar, J. L., Aiken, G. R., Bergamaschi, B. A., Fram, M. S., Fujii, R., and Mopper, K.: Evaluation of specific ultraviolet absorbance as an indicator of the chemical composition and reactivity of dissolved organic carbon, Environ. Sci. Technol., 37, 47024708, 2003.

Zhao, P., Zavarin, M., Leif, R. N., Powell, B. A., Singleton, M. J., Lindvall, R. E., and Kersting, A. B.: Mobilization of actinides by dissolved organic compounds at the Nevada Test Site, Appl. Geochem., 26, 308-318, 2011. 